\title{
Os Movimentos Populares no Magistério Social do Papa Francisco
}

\section{The Social Teaching of Pope Francis and the Popular Movements}

\author{
Paulo Fernando Carneiro de Andrade
}

\section{Resumo}

Entre 2014 e 2016 ocorreram três encontros do Papa Francisco com lideranças dos Movimentos Populares, organizados a pedido do Pontífice. Estes encontros, aqui analisados, constituem uma novidade e são expressão do novo paradigma que o Papa Francisco instaura na Doutrina Social da Igreja, onde emerge como elemento central a Opção Preferencial pelos Pobres na perspectiva desenvolvida pelo Episcopado Latino Americano de Medellín à Aparecida. Segundo esta perspectiva a Opção pelos Pobres possui dois elementos centrais. O primeiro é o que trata da mudança de lugar social, a identificação com o olhar do pobre, seus sofrimentos, alegrias e anseios, e o segundo refere-se a criar condições para que o pobre emerja como sujeito eclesial e sujeito social, ou seja, para que se torne sujeito da evangelização e protagonista das necessárias mudanças sociais. Nesta perspectiva, para o Papa Francisco os Movimentos Sociais são parte da Sociedade Civil e através deles os pobres se constituem como sujeitos fundamentais das necessárias transformações sociais que levem a uma superação da atual economia globalizada que, segundo o Papa, Mata, Exclui e Destrói a Mãe Terra, transformando o dinheiro em um ídolo ao qual tudo deve ser sacrificado.

Palavras-chave: Doutrina Social da Igreja. Papa Francisco. Movimentos Populares. 


\begin{abstract}
Between 2014 and 2016 there were three meetings of Pope Francis with leaders of the Popular Movements, organized at the request of the Pontiff. These meetings, analyzed here, are a novelty and are an expression of the new paradigm that Pope Francis establishes in the Social Doctrine of the Church, where the Preferential Option for the Poor emerges as a central element in the perspective developed by the Latin American Episcopate from Medellín to Aparecida. According to this perspective, the Option for the Poor has two central elements. The first is that which deals with the change of social place, the identification with the eyes of the poor, their sufferings, joys and desires, and the second refers to creating conditions for the poor to emerge as ecclesial and social subjects, in order to become the subject of evangelization and the protagonist of the necessary social changes. In this perspective, for Pope Francis the Social Movements are part of Civil Society and through them the poor constitute fundamental subjects of the necessary social transformations that lead to an overcoming of the current globalized economy that, according to the Pope, Mata, Excludes and Destroys the Mother Earth, turning money into an idol to which everything must be sacrificed.
\end{abstract}

Keywords: Catholic Social Teaching. Pope Francis. Popular Movements.

\title{
Introdução
}

O Magistério Pontifício do Papa Francisco tem se caracterizado por sua ênfase na Misericórdia Divina e no núcleo Ético Social do Cristianismo. Como Papa oriundo da Igreja Latino Americana, Francisco traz a rica experiência desta Igreja Continental para a Cátedra de Pedro. ${ }^{1}$ Desde os anos do pós-concílio, e sobretudo a partir da histórica reunião do Episcopado Latino Americano ocorrida em Medellín em 1968, a Igreja na América Latina se caracterizou por uma pastoral social centrada na opção pelos pobres e no apoio aos movimentos de transformação da realidade continental, marcada por profundas desigualdades, na direção de uma sociedade mais justa, fraterna e inclusiva. Esta pastoral, onde os pobres emergem como sujeitos eclesiais e

\footnotetext{
${ }^{1}$ Para a eclesiologia do Papa Francisco veja-se: CODINA, V., Espíritu e Iglesia en Francisco, p. $120-132$.
} 
sociais, traz como elemento inovador formas novas de relação entre a Igreja e a Sociedade que, de um lado, encontram-se apoiadas no desenvolvimento da Doutrina Social da Igreja que ocorre a partir do Concílio Vaticano II e, de outro, levam a um ulterior desenvolvimento desta mesma Doutrina Social, como se verifica no Magistério do Papa Francisco. Neste artigo, estudaremos no âmbito do desenvolvimento da Doutrina Social da Igreja a contribuição específica que traz Papa Francisco nos encontros mundiais com lideranças dos Movimentos Populares que ocorreram a partir de 2014, buscando compreender os aspectos inovadores destes encontros.

\section{O Desenvolvimento da Doutrina Social da Igreja de Leão XIII à João XXIII}

O Magistério Social da Igreja que se desenvolveu ao longo de toda a história da Igreja, desde seu início até os dias atuais, ganhou uma nova dimensão em 1891 com a promulgação da Encíclica Rerum Novarum de Leão XIII, ponto inicial da Doutrina Social da Igreja na Era Moderna. Esta Encíclica representa, de um lado, o ápice da construção de um novo paradigma da relação Igreja-Estado por parte de Leão XIII, e de outro lado, inaugura uma nova etapa no Magistério Social na Igreja que continuará a se desenvolver nas décadas seguintes com a promulgação de novas Encíclicas Sociais pelos Pontífices sucessivos, mantendo ao mesmo tempo uma certa organicidade e momentos de saltos paradigmáticos. Tendo como ponto de partida a Rerum Novarum, este conjunto de documentos pontifícios que constitui um específico corpo magisterial orgânico foi denominado Doutrina Social da Igreja. ${ }^{2}$ Quando Leão XIII ascendeu em finais do século XIX à Cátedra de Pedro, as transformações políticas, econômicas e sociais, iniciadas no século XVIII já eram uma realidade irreversível que se expandia por todo o mundo e a ilusão de um retorno ao Antigo Regime, derrubado pela Revolução Francesa e por movimentos políticos sociais que a partir da França se espalharam pelo mundo, não se colocava mais. A unificação italiana ocorrida em 1870 que acarretou o fim dos Estados Pontifícios e o avanço do movimento liberal burguês e do socialismo, seja na Europa seja nas Américas, exigia uma redefinição do

\footnotetext{
${ }^{2}$ Para o desenvolvimento do paradigma leoniano ver: HOLLAND, J., Modern Catholic Social Teaching. O tema dos sucessivos paradigmas na Doutrina Social da Igreja de Leão XIII a Francisco é desenvolvido de forma mais extensa no artigo de: ANDRADE, P., Um Novo paradigma na Doutrina Social da Igreja, p. 615-636.
} 
paradigma da relação Igreja-Estado-Mundo tal como se havia constituído e era vigente na Igreja até o fim do pontificado de Pio IX. Para se instituir o novo paradigma, desde a eleição de Leão XIII, foram promulgadas uma série de sete encíclicas que, entre 1878 e 1891, redefiniram a relação Igreja-Estado no mundo moderno. Em 1878 Leão XIII promulgou a Encíclica Quod Apostolici Numeris distinguindo o Socialismo do Capitalismo, antes vistos apenas como duas faces do Liberalismo, sendo ambos considerados adversários do cristianismo. Em relação ao Capitalismo Leão XIII admite a possibilidade da existência de uma versão não Liberal, tornando possível estabelecer então uma aliança com a nova classe dirigente, a burguesia, isolando assim o Socialismo como o grande adversário. Em 1879, a Encíclica Aeterni Patris redefiniu o programa cultural. A razão moderna não é mais vista como um todo monolítico a ser rejeitado em bloco. Propõe-se o realismo moderado e o neotomismo como alternativa ao racionalismo radical representado neste momento pelo Cientificismo seja na versão do Positivismo ou do Marxismo. Entre 1881 e 1890, quatro encíclicas delinearam o programa político: Diuturnum, 1881, sobre a natureza do poder político; Imortale Dei, 1885, sobre a teoria cristã do Estado; Libertas, 1888, sobre a natureza da liberdade humana; Sapientia Christianae, 1890, sobre o significado da cidadania. Passou-se aqui do ideal de restauração da Monarquia e do Absolutismo a um programa de reforma dos Estados Liberais, buscando sua conciliação com a doutrina cristã. Por fim, em 1891, a Encíclica Rerum Novarum completou o paradigma leoniano apresentando um programa econômico social onde se propõe o catolicismo social como expressão econômica dos Estados Liberais reformados.

Nesse novo paradigma, em continuidade com o paradigma anterior, não se diferencia de modo claro o Estado da Sociedade Civil. O Estado é afirmado como sendo natural, necessário e um bem. Segundo a interpretação leoniana da antropologia bíblica o ser humano é um ser social por natureza. Como ser criado para viver em comunidade ele necessita que exista uma instância de poder capaz de regular esta vida social. Nesta perspectiva, o Estado é compreendido como sendo uma estrutura necessária para a realização da vida social, regulando-a, cabendo a ele, a garantia da justiça, da ordem, a promoção do bem comum e da felicidade de seus membros. A autoridade civil (o governo do Estado) é tida como uma exigência que decorre da ordem da criação, tendo em vista que sem um princípio de autoridade o ser humano não poderia viver harmonicamente em comunidade e não poderia atingir o fim natural para o qual existe. Por isso é afirmado que o fundamento dessa 
autoridade não se encontra em uma delegação de poder dada pelos membros da sociedade aos governantes, mas em Deus. ${ }^{3}$ A teoria do pacto social e a perspectiva contratualista são frontalmente rejeitadas, sendo afirmado por Leão XIII que o:

Pacto que predicam é claramente uma ficção inventada que não serve para dar à autoridade política a força, a dignidade e a firmeza que requer a defesa da República e a utilidade comum dos cidadãos. A autoridade só terá esta majestade e fundamento universal se se reconhece que provém de Deus como de fonte Augusta e Santíssima. ${ }^{4}$

Para Leão XIII, o governante, isto é, quem exerce o governo, pode ser escolhido por diversos meios. Pode inclusive ser escolhido pelo voto de um colégio eleitoral ou pela maioria da população de um Estado, ${ }^{5}$ mas, mesmo nesse caso, a maioria estaria apenas designando quem exercerá autoridade, e não estaria conferindo autoridade ao governante. O princípio é o de que a origem última do poder se encontra em Deus, nesse caso, de modo mais próprio, na ordem que Deus dispôs para a criação, onde a existência da autoridade faz-se natural e necessária para a vida em comum. Note-se aqui que, embora se aceite o princípio da escolha da autoridade civil pelo voto majoritário, claramente não se aceita o princípio da soberania popular, fundamental nas democracias modernas, isto é, de que todo poder no Estado se exerce como delegação dada pelo povo.

Um outro ponto importante neste paradigma é a relação que se estabelece entre a Lei Eterna (os desígnios, ou plano, da Criação em Deus), a Lei Natural (a inscrição da Lei Eterna na ordem da Criação), a Lei Divina (A Revelação nas Escrituras dos Designíos de Deus para além do que se encontra na Lei Natural) e a Lei Positiva (o conjunto de Leis e Normas que regem cada Nação e a Comunidade Internacional). A Lei Positiva deve ser uma consolidação jurídica da Lei Natural e da Lei Divina. A autoridade exerce o poder legitimamente na medida em que defende e promove a Lei Positiva entendida nestes termos. Neste caso, embora se afirme a liberdade de consciência, não se admite a liberdade de expressão, pensamento ou associação como liberdade de se insurgir publicamente contra a Lei Positiva enquanto esta for a tradução

${ }^{3}$ Diuturnum Illud, 5; Immortale Dei, 4-5.

${ }^{4}$ Diuturnum Illud, 8.

${ }^{5}$ Diuturnum Illud, 6 . 
jurídica da Lei Natural e da Lei Divina, pois como afirma o aforisma: "o erro não gera direito". Este paradigma é reafirmado na Encíclica Quadragesimo Anno, de Pio XI promulgada em 1931, e por Pio XII em suas importantes rádio mensagens de Natal em 1942, 43 e 44. A Encíclica Mater e Magistra de João XXIII promulgada em 1961, representa uma transição para um outro paradigma que será instaurado pela Encíclica Pacem in Terris (João XXIII, 1963) e aprofundado no Documento Dignatis Humanae do Concílio Vaticano II (1965). Na Encíclica Pacem in Terris, João XXIII dirige-se não só aos Católicos, como se fazia nas Encíclicas Sociais anteriores, mas a todas as pessoas de boa vontade, e nesta Encíclica faz uma verdadeira recepção católica do paradigma dos Direitos Humanos, superando uma compreensão da relação entre indivíduo e Estado que tem como ponto de partida os deveres do cidadão e que tem como princípio a defesa do Estado frente a uma possível ação desagregadora do indivíduo. Nela são afirmados um conjunto de Direitos que ultrapassa os constantes na Declaração Universal dos Direitos Humanos das Nações Unidas de 1948, desdobrando-se estes direitos em quatro dimensões que permanecem unidas: direitos políticos, civis, econômicos e sociais. Ao integrar os direitos individuais aos sociais a partir do princípio da responsabilidade social e do dever de solidariedade que liga as pessoas humanas, esta perspectiva se distingue claramente da visão liberal dos Direitos Humanos. ${ }^{6}$

\section{O Paradigma Democrático na Dignatis Humanae e distinção entre Estado e Sociedade Civil}

Se João XXIII inaugurou na Encíclica Pacem in Terris um novo paradigma na Doutrina Social da Igreja ao recepcionar no Magistério Pontifício a doutrina ético-jurídica dos Direitos Humanos, coube à declaração Conciliar Dignatitis Humanae aprovada em 1965, ao final do Concílio Vaticano II, recepcionar plenamente a concepção moderna de Estado Democrático de Direito no Magistério Católico. Nela ocorre uma substancial mudança de paradigma na concepção da relação Igreja-Estado e na forma de conceber a relação Verdade-Moral-Lei. Essa mudança foi possível graças à teologia desenvolvida no ambiente Norte Americano, desde os anos 40, pelo teólogo jesuíta John Courtney Murray, e representa o ultrapassar da última barreira na direção da

\footnotetext{
${ }^{6}$ CURRAN, C., Churches and Human Rights, p. 38-61.
} 
real aceitação do paradigma democrático contemporâneo pela Doutrina Social da Igreja: a recepção plena da legitimidade das liberdades democráticas, incluindo a liberdade religiosa, a liberdade de defender livremente suas ideias e de viver segundo sua vontade, desde que não prejudique a outros, superando o paradigma tomista-leoniano. A argumentação fundamental do novo paradigma de John Courtney Murray acerca da relação Igreja e Estado que foi assumido pelos Padres Conciliares na Declaração Dignatis Humanae se desenvolve em torno a quatro pontos. ${ }^{7}$ Primeiro J. C. Murray toma como ponto de partida a distinção tradicional entre a ordem espiritual e a temporal. Nesta perspectiva, Igreja e Estado têm diferentes finalidades, segundo as duas distintas ordens a que pertencem. Entre as duas ordens existe uma articulação que se encontra na realidade mesma da Igreja: cada fiel católico, membro da Igreja, é também cidadão e nesta condição é membro de um Estado. Como segundo ponto, J. C. Murray estabelece uma distinção fundamental entre o Estado e a Sociedade Civil. Estado e Sociedade Civil não são co-extensivos, não se confundem. O Estado Moderno, por princípio, possui o monopólio do poder coercitivo e deve exercê-lo apenas para proteger e garantir a justiça e a paz pública. O fim da Sociedade Civil é maior e qualitativamente diferente do que o do Estado. Em um regime democrático, o Estado possui um papel restrito, delimitado pelos princípios constitucionais e é obrigado a respeitar a diversidade de seus membros, protegendo as minorias do abuso das maiorias. Além disso, segundo o princípio de subsidiariedade consagrado na Doutrina Social da Igreja, a Sociedade e o Estado devem ser concebidos de sua base para cima, não podendo o Estado anular a Sociedade Civil ou submetê-la a si. O terceiro ponto encontra-se no fato de que a distinção entre Sociedade e Estado permite que, por sua vez, se distinga o Bem Comum da Ordem Pública. Para J. C. Murray, o fim da Sociedade Civil é a construção do Bem Comum, enquanto o do Estado é a promoção da Ordem Pública para que a Sociedade Civil possa chegar ao Bem Comum. Por Ordem Pública, entende Murray, a garantia da justiça, da paz (harmonia social) e da moralidade pública. A moralidade pública não se confunde com a moralidade privada, e para J. C. Murray, diz respeito àquilo que afeta a paz pública e a justiça. A justiça abarca, por sua vez, os Direitos Fundamentais da pessoa humana e incluem também os Direitos difusos e ecológicos. A distinção entre o fim do Estado que é

\footnotetext{
${ }^{7}$ Dentre os muitos escritos de J. C. Murray sobre o tema, veja-se de modo especial: MURRAY, J. C., The Declaration on Religious Freedom, p. 3-12 e MURRAY, J. C., On the Structure of the Church-State Problem, p. 11-32.
} 
basicamente a garantia da Justiça, ou seja, dos Direitos Fundamentais em suas seis dimensões (políticos, civis, econômicos, sociais, culturais e ecológicos) e o fim da Sociedade, que é a construção do Bem Comum, é fundamental para se conceber de um novo modo a relação Igreja-Estado. Então, por fim, J. C. Murray enuncia um quarto ponto, que é de certo modo um corolário dos três anteriores: o Estado Democrático de Direito deve garantir tanta liberdade, pessoal e social, quanto possível, e restringir a liberdade apenas naquilo que for necessário para a ordem pública (Justiça). Esse princípio constitui-se no ponto fundamental da Declaração Dignatis Humanae:

\begin{abstract}
Além disso, uma vez que a sociedade civil tem o direito de se proteger contra os abusos que, sob pretexto de liberdade religiosa, se poderiam verificar, é sobretudo ao poder civil que pertence assegurar esta proteção. Isto, porém, não se deve fazer de modo arbitrário, ou favorecendo injustamente uma parte; mas segundo as normas jurídicas, conformes à ordem objetiva, postuladas pela tutela eficaz dos direitos de todos os cidadãos e sua pacífica harmonia, pelo suficiente cuidado da honesta paz pública que consiste na ordenada convivência sobre a base duma verdadeira justiça, e ainda pela guarda que se deve ter da moralidade pública. Todas estas coisas são parte fundamental do bem comum e pertencem à ordem pública. De resto, deve manter-se o princípio de assegurar a liberdade integral na sociedade, segundo o qual se há de reconhecer ao homem o maior grau possível de liberdade, só restringindo esta quando e na medida em que for necessário. ${ }^{8}$
\end{abstract}

Com a recepção do chamado "paradigma da liberdade religiosa" chegase no Magistério da Igreja à plena aceitação do paradigma contemporâneo da Democracia, que inclui uma nova perspectiva na relação entre Moral e Lei. Em um Estado Democrático de Direito a Lei não é pensada como garantia da moralidade individual, mas da Justiça, ou seja, ela deve restringir a liberdade individual e social apenas para garantir a Justiça, ou seja, os Direitos Fundamentais. ${ }^{9}$

Este princípio é plenamente acolhido na Doutrina Social da Igreja, de Paulo VI em diante. ${ }^{10}$ Assim, segundo a Carta Apostólica de Paulo VI

\footnotetext{
${ }^{8} \mathrm{DH} 7$, grifo nosso.

${ }^{9}$ Veja-se aqui: GRASSO, K.; HUNT, R. (Eds.)., Catholicism and Religious Freedom.

${ }^{10}$ Veja-se aqui o desenvolvimento detalhado desta questão que fiz em ANDRADE, P., Democracia e Doutrina Social da Igreja, p. 171-209.
} 
Octogesima Adveniens, promulgada em 1971 para comemorar os 80 anos da publicação da Rerum Novarum, a ação política, por parte dos cristãos se faz como forma de viver o compromisso cristão, como serviço ao outro, na busca de construir o bem comum e uma sociedade mais justa ${ }^{11}$ e não para impor, através do Estado, uma particular convicção. Nas palavras da Octogesima Adveniens:

A ação política - será necessário acentuar que se trata prevalentemente de uma ação e não de uma ideologia? - deve ter como base de sustentação um esquema de sociedade, coerente nos meios concretos que escolhe e na sua inspiração, que deve alimentar-se numa concepção plena da vocação do homem e das suas diferentes expressões sociais. Não compete nem ao Estado, nem sequer aos partidos políticos, que estariam fechados sobre si mesmos, procurar impor uma ideologia, por meios que viessem a redundar em ditadura dos espíritos, a pior de todas. $E$ sim aos grupos culturais e religiosos - salvaguardada a liberdade de adesão que eles pressupõem - que assiste o direito de, pelas suas vias próprias e de maneira desinteressada, desenvolverem no corpo social essas conviç̧ões supremas acerca da natureza, da origem e do fim do homem e da sociedade. Neste ponto, é oportuno recordar o princípio proclamado no recente Concílio Vaticano II: "A verdade não se impõe de outro modo senão pela sua própria força de verdade, que penetra nos espíritos, ao mesmo tempo suave e fortemente [Dignitatis Humanae 1]". ${ }^{12}$

Aqui se assume plenamente a distinção ente Estado e Sociedade Civil. É esta perspectiva que leva Bento XVI, alguns anos depois, a afirmar na Encíclica Deus Caritas Est (2005) que:

A justiça é o objetivo e, consequentemente, também a medida intrínseca de toda a política. A política é mais do que uma simples técnica para a definição dos ordenamentos públicos: a sua origem e o seu objetivo estão precisamente na justiça, e esta é de natureza ética. Assim, o Estado defronta-se inevitavelmente com a questão: como realizar a justiça aqui e agora? Mas esta pergunta pressupõe outra mais radical: o que é a justiça? ${ }^{13}$

${ }^{11} \mathrm{OA} 23-24$ e 46.

${ }^{12}$ OA 25, grifos nossos.

${ }^{13}$ DCE 28. 
Se de um lado a medida de toda a justiça é o objetivo de toda a política, cabe à Sociedade Civil e às suas organizações o empenho pela construção do Bem Comum, assim como também promover ações para que o Estado (que inclui os poderes executivo, legislativo e jurídico com todos os seus organismos próprios) tenha de fato como objetivo e propósito a realização da Justiça, compreendida como a defesa e promoção dos Direitos Humanos e da Terra em todas as suas dimensões.

\section{Papa Francisco e um novo desenvolvimento da Doutrina Social da Igreja: a importância dos Movimentos Populares}

O Magistério Social do Papa Francisco instaura na Doutrina Social da Igreja um novo paradigma no qual a Igreja convoca ao diálogo e à ação, e se propõe a ouvir e a apresentar a riqueza de sua Tradição, com a certeza de que esta, aberta à colaboração de outros saberes e experiências, constitui-se em uma importante contribuição para que se possam superar os graves problemas de nosso tempo. ${ }^{14}$ Neste novo paradigma, notadamente na Encíclica Laudato Si' (2015), constata-se que estamos vivendo uma gravíssima crise social e ambiental, que constituem na verdade uma única crise com diversas dimensões, tendo como causa uma mesma raiz. Deste modo, para sublinhar a unidade e o nexo das duas dimensões da crise que vivemos hoje deve-se afirmar que vivemos uma única e grave crise socioambiental. Para o Papa Francisco esta crise é o resultado de uma economia concreta, que se tornou hoje hegemônica, que exclui os pobres, mata pessoas e destrói a natureza levando a uma situação que brevemente pode se tornar irreversível e que coloca em risco o futuro da existência da humanidade. Outra característica do novo paradigma de Francisco é a de que em seu Magistério Pontifício a Opção pelos Pobres, tal como foi desenvolvida na Teologia e no Magistério Latino Americano de Medellín à Aparecida, é recepcionada em profundidade. ${ }^{15} \mathrm{O}$ pobre é reconhecido como um sujeito eclesial e político-social autêntico. Os Pobres, destinatários privilegiados da Boa Nova, possuem um papel fundamental, seja como Sujeito Eclesial da Evangelização, seja como Sujeito Social e Político que tem de modo particular a possibilidade e a responsabilidade de construir uma nova

\footnotetext{
${ }^{14}$ PIÉ-NINOT, S., La eclesiología del Papa Francisco, p. 255-286.

${ }^{15}$ NOGUIERA, A. R. V., Igreja dos pobres como nota da Igreja e marca da espiritualidade cristã, p. 606-621; AQUINO JUNIOR, F. A., "Igreja dos pobres”, p. 332-362; PEREIRA, S. C., O legado da "Igreja dos pobres" para a Igreja na América Latina, p. 22-37.
} 
ordem mundial que leve à superação da atual crise socioambiental. O Papa Francisco afirma a necessidade de reformas estruturais urgentes que possam levar à superação desta economia globalizada e das estruturas por ela geradas que produzem morte e destruição, que sacrificam muitas pessoas e a natureza mesma, para o benefício de uns poucos. A Economia deve ser subordinada à vida. É Missão da Igreja anunciar por Palavras e Gestos a Salvação trazida por Cristo que se destina a todo o Criado. Em função da Missão recebida de Cristo, cabe à Igreja e aos cristãos uma grande responsabilidade na luta pela superação da atual crise socioambiental. ${ }^{16}$

Neste contexto surge no Magistério e na ação pastoral do Papa Francisco uma especial relação com os Movimentos Populares. Nas Sociedades Democráticas Modernas multiplicaram-se as instâncias e instituições através dos quais os cidadãos buscam participar das definições e dos rumos das políticas e ações desenvolvidas pelo Estado. A Teologia e a Prática Pastoral latino-americana e particularmente a corrente argentina da Teologia da Libertação, conhecida como Teologia do Povo, ${ }^{17}$ enfatizaram sempre o papel social transformador e insubstituível dos pobres organizados nos Movimentos Populares, que constituem um parte expressiva dos Movimentos Sociais. São estes Movimentos que podem promover a verdadeira transformação das estruturas sociais e econômicas. Eles fazem parte da Sociedade Civil e não das estruturas de Estado, embora se dirijam ao Estado e interajam intensamente com este na busca de que o mesmo responda às suas propostas e reivindicações. São constituídos a partir da base da sociedade, reunindo os setores populares que se organizam e que através deles podem, além de promover ações que tragam benefícios para uma região, um bairro, uma classe de trabalhadores, ter voz e força mobilizadora capaz de influir decididamente na defesa de direitos e na definição das políticas de Estado. Os Movimentos Populares não substituem nem cancelam os partidos políticos. Não são uma alternativa aos Partidos, que continuam imprescindíveis nas estruturas dos Estados Democráticos de Direito, pois sem eles não se pode pensar em uma verdadeira democracia representativa, e se deve ter presente, ainda, que o enfraquecimento ou anulação dos partidos políticos como propõem hoje as diversas formas de Populismo leva inevitavelmente ao Autoritarismo, como podemos verificar em muitos países. ${ }^{18}$ Mas, por sua vez, os Movimentos Populares são também

\footnotetext{
${ }^{16}$ LS 7-9; EG 182-192.

${ }^{17}$ SCANNONE, J. C., A Teologia do povo; CUDA, E., Leggere Francesco.

${ }^{18}$ GRAZIANO, P., Neopopulismi.
} 
necessários à democracia contemporânea para que a ação político partidária não se transforme em algo absoluto e em única possibilidade de expressão política afastando e alienando grande parte da população, em especial os setores populares, dos processos decisórios e da construção de uma sociedade mais justa e igualitária. Sem os Movimentos Populares a Política tende a se esclerosar e a burocratizar-se perdendo sua força transformadora e tornandose um mero instrumento de dominação e de manutenção do status quo. Por esta razão, a Igreja na América Latina sempre promoveu um profundo engajamento do laicato na criação dos Movimentos Populares, como forma de empoderamento dos setores empobrecidos e marginalizados e de se promover a justiça social e a construção de uma sociedade mais justa e igualitária, em comunhão com a Doutrina Social da Igreja. Decorre deste contexto o apreço do Papa Francisco aos Movimentos Populares. ${ }^{19}$ Entre 2014 e 2016 ocorreram três encontros do Papa Francisco com lideranças dos Movimentos Populares, organizados pela Pontifícia Comissão de Justiça e Paz. Foram ocasião de diálogo e nelas o Papa pronunciou três discursos que expressam de modo claro o Magistério Social do atual Pontífice. Posteriormente, em 2017 envia também uma Mensagem aos participantes do Encontro dos Movimentos populares realizado em Modesto, Califórnia (16-19 de fevereiro) e na Páscoa de 2020, em meio à pandemia causada pelo coronavírus, o Papa endereçou ainda uma nova Carta aos Movimentos Populares.

\subsection{O Primeiro Encontro do Papa Francisco com os Movimento Populares}

O primeiro encontro do Papa Francisco com os Movimentos Populares ocorreu no Vaticano, entre os dias 27 a 29 de outubro de 2014 com a presença de cerca de 160 representantes dos Movimentos Populares de todo o mundo. Este primeiro encontro convocado pelo Papa através da Pontifícia Comissão

\footnotetext{
${ }^{19}$ IVEREIGH, A., Wounded shepherd, p. 11: "Francis wants the workers to organize for change, to band together against the new harsh winds of the global economy: 'only by joining forces can we say 'no' to the unfairness which generates violence', he tells them. The following month in Bolivia he would give his second rousing speech to the 'popular movements', mobilizing them in favor of another kind of globalized modernity, one that didn't make shareholder profit the main criterion of economic organization, but the right of all to land, labor, and lodging. When Francis spoke like this he was called Marxist, but it was an old call, repeated by popes across the twentieth century, for the markets to work for the many, not the few, the kind of thing President Juan D. Perón tried to create in Francis's childhood Argentina, or Franklin D. Roosevelt in the United States".
} 
Justiça e Paz, contou para sua execução também com a colaboração da Pontifícia Academia de Ciências. O Encontro, que foi precedido por um seminário realizado em Roma em 2013, foi organizado em torno a três eixos temáticos: Terra, Teto (Moradia) e Trabalho. No dia 28 de outubro, na exsala do Sínodo, o Papa pronunciou um histórico discurso aos Movimentos Populares. Já no início de seu discurso o Papa sublinha o fato de que os movimentos Populares são expressão do protagonismo dos pobres na luta pela justiça e pela transformação social. Através dos Movimentos Populares os pobres se tornam sujeitos da história:

Este encontro dos Movimentos populares é um sinal, um grande sinal: viestes apresentar diante de Deus, da Igreja e dos povos uma realidade que muitas vezes passa em silêncio. Os pobres não só suportam a injustiça mas também lutam contra ela!... Vós sentis que os pobres não esperam mais e querem ser protagonistas; organizam-se, estudam, trabalham, exigem e sobretudo praticam aquela solidariedade tão especial que existe entre quantos sofrem, entre os pobres, e que a nossa civilização parece ter esquecido, ou pelo menos tem grande vontade de esquecer. ${ }^{20}$

O Papa também afirma que os Movimentos Populares "fazem história" ao lutar "contra as causas estruturais da pobreza e desigualdade, a falta de trabalho, a terra e a casa, a negação dos direitos sociais e laborais". Esta análise de que a pobreza, a exclusão social e a destruição da natureza possuem causas econômicas estruturais, que não são simples efeito de políticas que podem ser corrigidas de modo superficial, torna-se central no seu Magistério Social. Papa Francisco afirma: "Não se pode enfrentar o escândalo da pobreza promovendo estratégias de contenção que só tranquilizam e transformam os pobres em seres domesticados e inofensivos". ${ }^{21}$

Ao abordar o tema da Terra, da Casa e do Trabalho, o Papa afirma a centralidade da pessoa humana, denuncia a destruição da Natureza, os processos de marginalização nas cidades e de gentrifugação que afasta os pobres para a periferia, lhes tira e nega uma moradia digna e uma economia que produz uma cultura do descarte, onde o que não é fonte de lucro para o capital, inclusive pessoas, é colocado à margem. Assim, crianças, jovens,

${ }^{20}$ FRANCISO, PP., Discurso do Papa Francisco aos participantes no Encontro Mundial dos Movimentos Populares.

${ }^{21}$ FRANCISO, PP., Discurso do Papa Francisco aos participantes no Encontro Mundial dos Movimentos Populares. 
idosos são afastados do mercado, descuidados, condenados a uma vida indigna ou mesmo abandonados para morrer. Trata-se de "um sistema econômico centrado no deus dinheiro" que tem necessidade de "saquear a natureza para manter o ritmo frenético de consumo que lhe é próprio" e que sacrifica vidas em seu altar. ${ }^{22}$

Para o Papa, os Movimentos Populares buscam transformar esta realidade criando alternativas de trabalho popular, lutando pela preservação ambiental, pela moradia, pelo trabalho buscando revitalizar os processos democráticos para que se alcance uma transformação das estruturas através da participação dos setores populares, enquanto parte da Sociedade Civil organizada, nos processos decisórios:

Os movimentos populares expressam a necessidade urgente de revitalizar as nossas democracias, tantas vezes desviadas por inúmeros factores. É impossível imaginar um futuro para a sociedade sem a participação como protagonistas das grandes maiorias e este protagonismo transcende os procedimentos lógicos da democracia formal. A perspectiva de um mundo de paz e de justiça duradouras pede que superemos o assistencialismo paternalista, exige que criemos novas formas de participação que incluam os movimentos populares e animem as estruturas de governo locais, nacionais e internacionais com aquela torrente de energia moral que nasce da integração dos excluídos na construção do destino comum. E assim com ânimo construtivo, sem ressentimento, com amor. ${ }^{23}$

O Papa se despede afirmando que acompanha os Movimentos Populares neste caminho.

\subsection{O Segundo Encontro do Papa Francisco com os Movimentos Populares}

Por ocasião de sua viagem ao Equador, Bolívia e Paraguai, que se deu entre os dias 5 a 13 de julho de 2015, o Papa Francisco esteve presente em 9 de julho em Santa Cruz de la Sierra, Bolívia no II Encontro Mundial dos Movimentos Populares. Neste novo encontro, mais massivo, estiveram presentes cerca de 1500 participantes dos quais 600 eram bolivianos e os outros provenientes de

${ }^{22}$ FRANCISO, PP., Discurso do Papa Francisco aos participantes no Encontro Mundial dos Movimentos Populares.

${ }^{23}$ FRANCISO, PP., Discurso do Papa Francisco aos participantes no Encontro Mundial dos Movimentos Populares. 
diversas partes do mundo. Como o primeiro, este encontro teve por objetivo tecer uma alternativa popular à globalização excludente à luz do pensamento social do Papa Francisco. A escolha da Bolívia para sediar esta reunião se deveu ao processo de organização das forças populares que hoje existe neste país.

No seu novo discurso o Papa coloca ênfase, sobretudo, na necessidade urgente de mudanças estruturais. O Pontífice sublinha que um elo invisível une cada uma das injustiças e exclusões que ocorrem nas atividades laborais e em cada bairro e cada território. Trata-se de "um sistema que se tornou global", um "sistema que impôs a lógica do lucro a todo custo, sem pensar na exclusão social nem na destruição da natureza". É necessária uma mudança real, uma mudança de estruturas global. A economia e as estruturas econômicas têm de ser mudadas. A atual economia é idólatra. O Pontífice afirma:

Quando o capital se torna um ídolo e dirige as opções dos seres humanos, quando a avidez do dinheiro domina todo o sistema socioeconômico, arruína a sociedade, condena o homem, transforma-o em escravo, destrói a fraternidade inter-humana, faz lutar povo contra povo e até, como vemos, põe em risco esta nossa casa comum, a irmã e mãe terra. (...) Os seres humanos e a natureza não devem estar ao serviço do dinheiro. Digamos NÃO a uma economia de exclusão e desigualdade, onde o dinheiro reina em vez de servir. Esta economia mata. Esta economia exclui. Esta economia destrói a Mãe Terra. ${ }^{24}$

Segundo o Pontífice aos Movimentos Populares cabem três grandes tarefas. A primeira é a de "pôr a economia a serviço dos povos", mudando radicalmente a estrutura econômica atual construindo uma economia "onde o ser humano, em harmonia com a natureza, estrutura todo o sistema de produção e distribuição de tal modo que as capacidades e necessidades de cada um encontrem um apoio adequado no ser social". A segunda tarefa consiste em "unir os nossos povos no caminho da paz e da justiça", onde se insere a luta contra as velhas e novas formas de colonialismo. O Papa afirma:

O colonialismo, novo e velho, que reduz os países pobres a meros fornecedores de matérias-primas e mão de obra barata, gera violência, miséria, emigrações forçadas e todos os males que vêm juntos... precisamente porque, ao pôr a periferia em função do centro, nega-lhes o

\footnotetext{
${ }^{24}$ FRANCISO, PP., Discurso do Papa Francisco aos participantes no II Encontro Mundial dos Movimentos Populares.
} 
direito a um desenvolvimento integral. $\mathrm{E}$ isto, irmãos, é desigualdade, e a desigualdade gera violência que nenhum recurso policial, militar ou dos serviços secretos será capaz de deter. ${ }^{25}$

A terceira tarefa, de fundamental importância, consiste em defender a Mãe Terra, ameaçada pelo sistema econômico vigente. Sem um forte engajamento nesta luta por salvar a Mãe Terra a vida humana pode se extinguir.

Por fim o Papa ressalta mais uma vez na conclusão de seu discurso a importância fundamental dos Movimentos Populares para o futuro dos povos e para que se produzam as necessárias mudanças estruturais, capazes de nos levar à superação da grave crise socioambiental:

\begin{abstract}
Para concluir, quero dizer-lhes novamente: $\mathrm{O}$ futuro da humanidade não está unicamente nas mãos dos grandes dirigentes, das grandes potencias e das elites. Está fundamentalmente nas mãos dos povos; na sua capacidade de se organizarem e também nas suas mãos que regem, com humildade e convicção, este processo de mudança. Estou convosco. E cada um, repitamos a nós mesmos do fundo do coração: nenhuma família sem teto, nenhum camponês sem terra, nenhum trabalhador sem direitos, nenhum povo sem soberania, nenhuma pessoa sem dignidade, nenhuma criança sem infância, nenhum jovem sem possibilidades, nenhum idoso sem uma veneranda velhice. Continuai com a vossa luta e, por favor, cuidai bem da Mãe Terra. ${ }^{26}$
\end{abstract}

A dimensão estrutural da ordem econômica e social que é fortemente sublinhada pelo Papa Francisco constitui uma nova perspectiva na Doutrina Social da Igreja. Já pontífices anteriores tinham feito referências a estruturas econômicas que podem se tornar verdadeiras estruturas de pecado, como aparece em João Paulo II. ${ }^{27}$ Mas a ênfase nas estruturas econômicas tal como faz Francisco desde sua Exortação Apostólica Evangelii Gaudium ${ }^{28}$ encontrase em continuidade com a tradição magisterial latino-americana e constitui uma novidade no Magistério Pontifício.

\footnotetext{
${ }^{25}$ FRANCISO, PP., Discurso do Papa Francisco aos participantes no II Encontro Mundial dos Movimentos Populares.

${ }^{26}$ FRANCISO, PP., Discurso do Papa Francisco aos participantes no II Encontro Mundial dos Movimentos Populares.

${ }^{27}$ SRS 36.

${ }^{28}$ EG 52-60.
} 


\subsection{O Terceiro Encontro do Papa com os Movimentos Populares}

O Terceiro encontro do Papa Francisco com os Movimentos Populares ocorreu em Roma, no dia 5 de novembro de 2016. Nele estiveram presentes delegados que vieram das periferias urbanas, rurais e industriais de mais de 60 países de todos os continentes. $\mathrm{O}$ encontro contou também com a presença do ex-presidente uruguaio José Mojica. O Papa inicia seu discurso reafirmando que neste encontro quer expressar em continuidade com os dois primeiros, "a mesma sede, a sede de justiça, o mesmo grito: terra, casa e trabalho para todos". ${ }^{29}$

Neste terceiro encontro o Papa aborda em seu discurso três novos temas. O primeiro ele denomina "O terror e os muros". Francisco recorda que na Bolívia havia falado de um fio invisível (uma estrutura) que une toda injustiça e exclusão que os pobres padecem. Trata-se do dinheiro divinizado, que governa o mundo usando o "chicote do medo, da desigualdade, da violência financeira, social, cultural e militar que gera cada vez mais violência numa espiral descendente que parece infinita". Trata-se de um "terrorismo de base que provém do controle global do dinheiro na terra, ameaçando a humanidade inteira". Segundo Francisco "é deste terrorismo de base que se alimentam os terrorismos derivados, como o narcoterrorismo, o terrorismo de Estado e aquele que alguns erroneamente chamam de terrorismo étnico ou religioso". Francisco, em continuidade com toda a Tradição da Igreja, denuncia vigorosamente: o "ídolo dinheiro, que reina em vez de servir, tiraniza e aterroriza a humanidade". Esta tirania é terrorista, para se sustentar explora os nossos medos. Afirma o Papa:

E quando este terror, que foi semeado nas periferias com massacres, saques, opressões e injustiças, eclode nos centros sob várias formas de violência, até com atentados hediondos e infames, os cidadãos que ainda conservam alguns direitos são tentados pela falsa segurança dos muros físicos ou sociais. ${ }^{30}$

E assim alimenta-se a xenofobia, a segregação social, o ódio aos migrantes, e apoia-se a construção de muros reais e virtuais que buscam isolar

\footnotetext{
${ }^{29}$ FRANCISO, PP., Discurso do Papa Francisco aos participantes no III Encontro Mundial dos Movimentos Populares.

${ }^{30}$ FRANCISO, PP., Discurso do Papa Francisco aos participantes no III Encontro Mundial dos Movimentos Populares.
} 
o outro fora de nosso convívio. O medo torna-nos indiferente ao sofrimento do outro e alimenta a violência. O segundo ponto abordado pelo Papa é o do "Amor e pontes". Tendo como referência Mc 2,27. Jesus curou a mão atrofiada de um homem no sábado e isto colocou sua vida em risco. O Papa faz uma metáfora comparando a atrofia da mão à atrofia que o sistema econômico cria quando as pessoas são desprovidas da dignidade do trabalho. Através dos Movimentos Populares os pobres se organizam e agem, e o Papa afirma:

Inventais o vosso trabalho, criando uma cooperativa, recuperando uma fábrica falida, reciclando os descartes da sociedade consumista, enfrentando a inclemência do tempo para vender numa praça, reivindicando um pequeno pedaço de terra para cultivar e alimentar quem tem fome, quando fazeis isto imitais Jesus porque procurais curar, mesmo que seja só um pouco e de modo precário, esta atrofia do sistema socioeconómico imperante que é o desemprego. Não me surpreende que inclusive vós, por vezes, sois controlados ou perseguidos, e também não me causa admiração que os soberbos não se interessem por aquilo que vós dizeis. ${ }^{31}$

O sistema econômico vigente por vezes cria "próteses" cosméticas que não curam a atrofia, só a disfarça. Assim aparecem crescimento da economia, progressos tecnológicos, maior eficiência na produção de bens descartáveis, coisas que não levam ao desenvolvimento humano integral de cada um e de todos e ao respeito à criação.

O terceiro ponto tratado pelo Papa é denominado "Falência e resgate". O Papa trata aqui do drama dos migrantes, refugiados e dos deslocados. Ninguém deveria se ver obrigado a fugir de sua pátria. Mas a dura realidade impele tantos homens, mulheres e crianças a migrar. $\mathrm{O}$ encontro com as crianças nos campos de refugiados revela a falência da humanidade. Francisco afirma:

O que acontece com o mundo de hoje que, quando se verifica a falência de um banco, imediatamente aparecem quantias escandalosas para o salvar, mas quando ocorre esta falência da humanidade praticamente não aparece nem uma milésima parte para salvar aqueles irmãos que sofrem tanto? E assim o Mediterrâneo tornou-se um cemitério, e não apenas o Mediterrâneo... muitos cemitérios perto dos muros, muros manchados de

${ }^{31}$ FRANCISO, PP., Discurso do Papa Francisco aos participantes no III Encontro Mundial dos Movimentos Populares. 
sangue inocente. Nos dias deste encontro - sois vós que o dizeis no vídeo - quantos são os mortos no Mediterrâneo $?^{32}$

Dentro deste ponto o Papa aborda também a relação entre povo e democracia. Aqui o Papa torna a afirmar a especificidade dos Movimentos Populares:

Sei que os movimentos populares não são partidos políticos, e permiti-me dizer-vos que, em grande parte, é nisto que se encontra a vossa riqueza, porque exprimis uma forma diferente, dinâmica e vital de participação social na vida pública. Mas não tenhais medo de entrar nos grandes debates, na Política com letra maiúscula. ${ }^{33}$

Sendo parte da Sociedade Civil, não se confundem com os Partidos Políticos. Não obstante são organismos fundamentais para o estabelecimento de políticas públicas e para a revitalização da democracia. Através do Movimentos Populares a voz e a perspectiva dos pobres se tornam capazes de mudar a Política e de vencer a autonomia absoluta dos mercados e da especulação financeira e de atacar as causas estruturais da desigualdade social. Para isto os Movimentos Populares devem renunciar a tentação de se deixarem anular, sendo reduzidos a meros agentes de políticas complementares, e a tentação da corrupção, de se venderem ao Deus Dinheiro.

Na perspectiva de Francisco os Movimentos Populares são uma grande esperança para as mudanças necessárias em nosso mundo.

3.4. A Mensagem do Papa Francisco aos participantes no encontro dos Movimentos Populares em Modesto, Califórnia (fevereiro de 2017)

Nesta Mensagem escrita para os participantes de um encontro dos Movimentos Populares de nível nacional estadounidense, destacamse três pontos fundamentais que se relacionam com a realidade própria desse país. O primeiro consiste na ênfase na compaixão a partir de uma reflexão em torno da parábola do Bom samaritano. Como ele temos de nos aproximar dos feridos de hoje, cuidar pessoalmente das feridas que

${ }^{32}$ FRANCISO, PP., Discurso do Papa Francisco aos participantes no III Encontro Mundial dos Movimentos Populares.

${ }^{33}$ FRANCISO, PP., Discurso do Papa Francisco aos participantes no III Encontro Mundial dos Movimentos Populares. 
hoje são produzidas por um sistema econômico baseado na idolatria do dinheiro. Afirma Francisco:

As feridas provocadas pelo sistema da economia que tem no centro o deus dinheiro, e que às vezes age com a brutalidade dos ladrões da parábola, foram criminosamente ignoradas. Na sociedade globalizada, existe um estilo elegante de olhar para o outro lado, que se pratica de maneira recorrente: sob as aparências do politicamente correto ou das modas ideológicas, olhamos para aquele que sofre mas não o tocamos, transmitimo-lo ao vivo e até proferimos um discurso aparentemente tolerante e cheio de eufemismos, mas nada fazemos de sistemático para debelar as feridas sociais, nem sequer para enfrentar as estruturas que deixam tantos seres humanos na rua. Esta atitude hipócrita, tão diferente daquela do samaritano, manifesta a ausência de uma conversão autêntica e de um verdadeiro compromisso em prol da humanidade. ${ }^{34}$

A compaixão deve nos levar a nos identificarmos com os feridos pela estrada e a nos comprometer com a luta pela mudança de estruturas. Temos de nos tornar próximo dos necessitados. Os Movimentos Populares para o Papa assumiram este compromisso:

Nisto consiste a humanidade autêntica, resistente à desumanização que nos apresenta sob a forma da indiferença, da hipocrisia e da intolerância. Sei que assumistes o compromisso de lutar pela justiça social, de salvaguardar a irmã e mãe terra e de acompanhar os migrantes. Desejo confirmar-vos na vossa escolha e, a este propósito, partilhar convosco duas reflexões. ${ }^{35}$

O segundo ponto se encontra na afirmação de que a crise ecológica é real. E aqui Francisco afirma com toda força: "não devemos decair no negacionismo". O tempo começa a esgotar-se. Não são poucos os que nos Estados Unidos aderem a posições negacionistas que visam a proteger o império do capital, ao deus dinheiro. O terceiro ponto tem relação estreita com a cultura do medo e da xenofobia estimulada no ambiente político daquele país. Consiste na afirmação peremptória de Francisco de que:

${ }^{34}$ FRANCISO, PP., Discurso do Papa Francisco aos participantes no Encontro Mundial dos Movimentos Populares realizado em Modesto.

${ }^{35}$ FRANCISO, PP., Discurso do Papa Francisco aos participantes no Encontro Mundial dos Movimentos Populares realizado em Modesto. 
Nenhum povo é criminoso, nenhuma religião é terrorista. Não existe o terrorismo cristão, não existe o terrorismo judeu, não existe o terrorismo islâmico. Não existe! Nenhum povo é criminoso, nem narcotraficante, nem sequer violento. "Acusam-se da violência os pobres e as populações mais pobres, mas sem igualdade de oportunidades, as várias formas de agressão e de guerra encontrarão um terreno fértil que, mais cedo ou mais tarde, há de provocar a explosão" (Papa Francisco, Evangelii gaudium, n. 59). Existem pessoas fundamentalistas e violentas em todos os povos e em todas as religiões que, além disso, se revigoram com as generalizações intolerantes, alimentando-se com o ódio e a xenofobia. Enfrentando o terror com o amor, nós trabalhamos a favor da paz. ${ }^{36}$

O Papa afirma também em sua Mensagem:

Sabemos que nenhum destes males teve início ontem. Desde há tempos enfrentamos a crise do paradigma imperante, um sistema que causa sofrimentos enormes à família humana, atacando ao mesmo tempo a dignidade das pessoas e a nossa Casa Comum, para sustentar a tirania invisível do dinheiro, que garante apenas os privilégios de poucos. "A humanidade vive um momento histórico" (Papa Francisco, Evangelii gaudium, n. 52$).{ }^{37}$

\subsection{A Carta do Papa Francisco aos Movimentos Populares por ocasião da Pascoa de 2020}

Esta Carta foi escrita por Francisco em meio à pandemia causada pelo coronavirus. O Papa inicia sua Carta afirmando que no meio dessa pandemia ele se recorda dos participantes dos três Encontros dos Movimentos Populares e que, de um modo especial, quer estar perto deles. Francisco inicia sua Carta se referindo ao fato de muitos, neste trágico momento da pandemia, se refiram a ela usando metáforas bélicas. E neste contexto afirma:

Se a luta contra o COVID-19 é uma guerra, vocês são um verdadeiro exército invisível que luta nas trincheiras mais perigosas. Um exército sem outra arma senão a solidariedade, a esperança e o sentido da comunidade

${ }^{36}$ FRANCISO, PP., Discurso do Papa Francisco aos participantes no Encontro Mundial dos Movimentos Populares realizado em Modesto.

${ }^{37}$ FRANCISO, PP., Discurso do Papa Francisco aos participantes no Encontro Mundial dos Movimentos Populares realizado em Modesto. 
que reverdecem nos dias de hoje em que ninguém se salva sozinho. Vocês são para mim, como lhes disse em nossas reuniões, verdadeiros poetas sociais, que desde as periferias esquecidas criam soluções dignas para os problemas mais prementes dos excluídos. ${ }^{38}$

Segundo Francisco, os Movimentos Populares não são muitas vezes reconhecidos adequadamente, são inviabilizados, e por superarem a mera filantropia e reivindicarem direitos são vistos com suspeita. Eles não apenas denunciam, mas se colocam incessantemente a trabalhar pelas famílias, bairros, pelo bem comum. Trabalham junto aos que sofrem, cuidam, compartilham, se unem para curar. Muitos são hoje atingidos duplamente, pela vulnerabilidade sanitária e pela falta de garantias legais e econômicas que os protejam. Sem ter como viver, a quarentena se torna insuportável. Por isto Francisco afirma que é hora de se pensar em um salário universal que reconheça as necessidades e também as tarefas insubstituíveis que tantos trabalhadores informais realizam.

O Papa convida os Movimentos Populares a pensarem no depois:

Também gostaria de convidá-los a pensar no "depois", porque esta tempestade vai acabar e suas sérias consequências já estão sendo sentidas. Vocês não são uns improvisados, têm a cultura, a metodologia, mas principalmente a sabedoria que é amassada com o fermento de sentir a dor do outro como sua. Quero que pensemos no projeto de desenvolvimento humano integral que ansiamos, focado no protagonismo dos Povos em toda a sua diversidade e no acesso universal aos três T que vocês defendem: terra e comida, teto e trabalho. ${ }^{39}$

Esta tem sido para Francisco uma questão de extrema importância. A pandemia é um evento, um fato traumático que nos oferece uma oportunidade única de "nos repensar, nos regenerar". A idolatria do dinheiro, nos levou a uma catástrofe humanitária e ecológica. Agora temos de pensar em construir um novo mundo pós-pandemia, onde se "termine com a idolatria do dinheiro" e se "coloque a dignidade e a vida no centro". E os Movimentos Populares para Francisco "são construtores indispensáveis dessa mudança urgente; além disso, vocês possuem uma voz autorizada para testemunhar que isso é possível". ${ }^{40}$

${ }^{38}$ FRANCISO, PP., Carta do Papa Francisco aos Movimentos Populares.

${ }^{39}$ FRANCISO, PP., Carta do Papa Francisco aos Movimentos Populares.

${ }^{40}$ FRANCISO, PP., Carta do Papa Francisco aos Movimentos Populares. 


\section{Conclusão}

O Magistério social do Papa Francisco inaugura um novo paradigma na Doutrina Social da Igreja. A sua especial relação com os Movimentos Populares se insere plenamente dentro deste novo paradigma e através desta relação podemos perceber como este se objetiviza em novas práticas sociais e políticas. Em particular isto se pode constatar em ao menos 4 pontos que aqui destacamos como conclusão:

i. O Papa desde o início de seu Magistério parte da constatação de que vivemos uma terrível crise socioambiental. A destruição da natureza está atingindo um ponto do qual não se poderá mais retornar. A Terra não se poderá regenerar e caso isto ocorra será o fim da possibilidade da vida humana na Terra. Simultaneamente uma grande parcela da humanidade é privada do acesso aos meios necessários a uma vida digna, submetida a condições de trabalho desumanas, ou é mesma privada do acesso ao trabalho e aos bens mínimos necessários à sobrevivência, sofre violência de todos os tipos, vive um cotidiano de desamparo, onde encontra a morte precoce e evitável, enquanto uma pequena parcela acumula bens e usufrui de condições de vida infinitamente superior às necessidades vitais.

ii. A raiz desta crise socioambiental encontra-se em um sistema econômico que se tornou global e que tem como centro a idolatria do dinheiro. Tal sistema idólatra se configura em estruturas concretas, econômicas, sociais e culturais. Não basta denunciar esta idolatria do dinheiro, nem é suficiente um apelo à conversão dos corações. É necessário pôr fim à idolatria do dinheiro e promover uma profunda mudança estrutural, substituindo as atuais estruturas econômicosociais por novas estruturas. Só assim podemos superar a atual crise socioambiental.

iii. O Papa Francisco assume em profundidade em seu Magistério a Opção pelos Pobres tal como foi desenvolvida pelo Magistério dos Bispos Latino Americanos de Medellín à Aparecida. Tal Opção Evangélica expressa a especial relação de Deus com os Pobres, tal como é Revelado em toda a Escritura e de modo particular em Jesus mesmo. Francisco sublinha em seu Magistério as duas dimensões fundamentais da compreensão latino americana da 
Opção pelos Pobres: a) o chamado à mudança de lugar social, isto é a uma identificação com os sofrimentos, sonhos e anseios dos Pobres que se traduz também em uma vida simples e austera, e b) o reconhecimento dos Pobres como sujeitos privilegiados da Evangelização e das Mudanças Sociais na direção de uma sociedade mais justa, fraterna e ecologicamente respeitosa.

iv. A luta para superar a atual crise socioambiental e para pôr fim na idolatria do dinheiro deve ser comum a diversos atores na sociedade. Entre estes se encontram, no âmbito da Sociedade Civil, os pobres organizados nos Movimentos Populares. Francisco ao propor os encontros com os Movimentos Populares busca com eles dialogar, ouvi-los, animá-los e oferecer a perspectiva da ética social cristã como elemento de discernimento e encorajamento. Para Francisco, são os Pobres organizados nos Movimentos Populares que são capazes de dar uma contribuição fundamental para revitalizar as democracias contemporâneas e para construir uma nova Política que leve ao estabelecimento de uma nova ordem mundial.

\section{Referências bibliográficas}

ANDRADE, P. Democracia e Doutrina Social da Igreja. In: LESBAUPIN, I.; PINHEIRO, J. E. (Orgs.). Democracia, Igreja e Cidadania. São Paulo: Paulinas, 2010. p. 171-209.

ANDRADE, P. Um Novo paradigma na Doutrina Social da Igreja. REB, v. 79, n. 314, p. 615-636, set./dez. 2019.

AQUINO JUNIOR, F. A. "Igreja dos pobres": uma nota eclesiológica fundamental. Atualidade Teológica, v. 22, n. 59, p. 332-362, mai./ago. 2018. Disponível em: <https://www.maxwell.vrac.puc-rio.br/34476/34476. PDFXXvmi=>. Acesso em: 14 jul. 2020. DOI: https://doi.org./10.17771/ PUCRio.ATeo.34476

BENTO XVI, PP. Carta encíclica Deus Caritas Est. Disponível em: $<$ http:// www.vatican.va/content/benedict-xvi/pt/encyclicals/documents/hf_ben-xvi_ enc_20051225_deus-caritas-est.html>. Acesso em: 14 jul. 2020.

CODINA, V. Espíritu e Iglesia en Francisco. Atualidade Teológica, v. 22, n. 58, p. 120-132, jan./abr. 2018. Disponível em: <https://www.maxwell. 
vrac.puc-rio.br/32762/32762.PDFXXvmi=>. Acesso em: 14 jul. 2020. DOI: https://doi.org./10.17771/PUCRio.ATeo.32762

CONCÍLIO VATICANO II. Declaração Dignitatis Humanae sobre a liberdade religiosa. Disponível em: $<\mathrm{http} / / \mathrm{www} . v a t i c a n . v a / a r c h i v e / h i s t$ councils/ii_vatican_council/documents/vat-ii_decl_19651207_dignitatishumanae_po.html >. Acesso em: 14 jul. 2020.

CUDA, E. Leggere Francesco. Teologia, ética e política. Torino: Bollati Boringhieri ed, 2018.

CURRAN, C. Churches and Human Rights. From Hostility/Reluctance to Acceptability. In: CURRAN, C. (Ed.). Changes in Official Catholic Moral Teachings. New Jersey: Paulist Presss, 2003. p. 38-61. (Readings in Moral Theology, 13).

FRANCISO, PP. Carta do Papa Francisco aos Movimentos Populares, 12 abr. 2020. Disponível em: $<$ http://w2.vatican.va/content/francesco/pt/letters/2020/ documents/papa-francesco_20200412_lettera-movimentipopolari.html>. Acesso em: 14 jul. 2020.

FRANCISO, PP. Discurso do Papa Francisco aos participantes no Encontro Mundial dos Movimentos Populares, 28 out. 2014. Disponível em: $<\mathrm{http}: / /$ w2.vatican.va/content/francesco/pt/speeches/2014/october/documents/papafrancesco_20141028_incontro-mondiale-movimenti-popolari.html >. Acesso em: 14 jul. 2020.

FRANCISO, PP. Discurso do Papa Francisco aos participantes no II Encontro Mundial dos Movimentos Populares, 9 jul. 2015. Disponível em: $<$ http://w2.vatican.va/content/francesco/pt/speeches/2015/july/documents/papafrancesco_20150709_bolivia-movimenti-popolari.html >. Acesso em: 14 jul. 2020. FRANCISO, PP. Discurso do Papa Francisco aos participantes no III Encontro Mundial dos Movimentos Populares, 5 nov. 2016. Disponível em: <http://w2.vatican.va/content/francesco/pt/speeches/2016/november/ documents/papa-francesco_20161105_movimenti-popolari.html $>$. Acesso em: 14 jul. 2020.

FRANCISO, PP. Discurso do Papa Francisco aos participantes no Encontro Mundial dos Movimentos Populares realizado em Modesto, Califórnia, 10 fev. 2017. Disponível em: <http://w2.vatican.va/content/francesco/pt/ messages/pont-messages/2017/documents/papa-francesco_20170210_ movimenti-popolari-modesto.html>. Acesso em: 14 jul. 2020. 
GRASSO, K.; HUNT, R. (Eds.). Catholicism and Religious Freedom. Contemporary Reflections on Vatican II's Declaration on Religious Liberty. New York: Rowman \& Littlefield Publishers, 2006.

GRAZIANO, P. Neopopulismi. Perché sono destinati a durare. Bologna: Il Mulino, 2018.

HOLlAND, J. Modern Catholic Social Teaching. The Popes confront the industrial age 1740-1958. New York: Paulist Press, 2003.

IVEREIGH, A. Wounded shepherd: Pope Francis and his struggle to convert the Catholic Church. New York: Henry Holt and Company, 2019.

LEÃO XIII, PP. Carta encíclica Immortale Dei. Disponível em: $<$ http:// www.vatican.va/content/leo-xiii/pt/encyclicals/documents/hf_1-xiii_ enc_01111885_immortale-dei.html>. Acesso em: 14 jul. 2020.

LEÃO XIII, PP. Lettera enciclica Diuturnum Illud. Disponível em: $<$ http://www.vatican.va/content/leo-xiii/it/encyclicals/documents/hf_1-xiii_ enc_29061881_diuturnum.html>. Acesso em: 14 jul. 2020.

MURRAY, J. C. On the Structure of the Church-State Problem. In: GURIAN, W.; FITZSIMONS, M. A. (Eds.). The Catholic Church in World Affairs. Notre Dame: University of Notre Dame Press, 1954. p. 11-32.

MURRAY, J. C. The Declaration on Religious Freedom. In: CURRAN, C. (Ed.). Changes in Official Catholic Moral Teachings. New Jersey: Paulist Presss, 2003. p. 3-12. (Readings in Moral Theology, 13).

NOGUIERA, A. R. V. Igreja dos pobres como nota da Igreja e marca da espiritualidade cristã: uma reflexão a partir de Jon Sobrino e do Papa Francisco. Atualidade Teológica, v. 19, n. 51, p. 606-621, set./dez. 2015. Disponível em: <https://www.maxwell.vrac.puc-rio.br/25942/25942. PDFXXvmi=>. Acesso em: 14 jul. 2020. DOI: https://doi.org./10.17771/ PUCRio.ATeo.25942

PAULO VI, PP. Carta apostólica Octogesima Adveniens. Disponível em: $<$ http://www.vatican.va/content/paul-vi/pt/apost_letters/documents/hf_p-vi_ apl_19710514_octogesima-adveniens.html $>$. Acesso em: 14 jul. 2020.

PEREIRA, S. C. O legado da "Igreja dos pobres" para a Igreja na América Latina. Pesquisas em Teologia,v. 1, n. 1, p.22-37, jan./jun. 2018. Disponível em: <http://periodicos.puc-rio.br/index.php/pesquisasemteologia/article/ view/682/499>. Acesso em: 14 jul. 2020. DOI: http://dx.doi.org/10.46859/ PUCRio.Acad.PqTeo.2595-9409.2018v1n1p22 
PIÉ-NINOT, S. La eclesiología del Papa Francisco. Atualidade Teológica, v. 22, n. 59, p. 255-286, mai./ago. 2018. Disponível em: $<$ https://www.maxwell. vrac.puc-rio.br/34471/34471.PDFXXvmi=>. Acesso em: 14 jul. 2020. DOI: https://doi.org./10.17771/PUCRio.ATeo.34471

SCANNONE, J. C. A Teologia do povo. Raízes teológicas do Papa Francisco. Paulinas: São Paulo, 2019.

Paulo Fernando Carneiro de Andrade Doutor em Teologia pela Pontificia Università Gregoriana Docente do Departamento de Teologia da Pontifícia Universidade

Católica do Rio de Janeiro Rio de Janeiro / RJ - Brasil E-mail: paulof@puc-rio.br

Recebido em: 14/07/2020 Aprovado em: 09/11/2020 